\title{
Diálogos entre cultura e formação do sistema literário nacional: $O$ entrecruzar Brasil e Cabo Verde a partir de Memórias póstumas de Brás Cubas e $O$ testamento do senhor Napumoceno.
}

\author{
Ana Maria Lange Gomes ${ }^{1}$
}

\begin{abstract}
RESUMO: Machado de Assis e Germano Almeida são escritores representativos no cenário literário de seus países, que além de terem obras literárias significativas, se empenharam na reflexão da construção do sistema literário de seus países e participaram das discussões acerca do processo de formação. Desta forma, este artigo pretende investigar características destes processos de ambos os países partindo da reflexão das obras Memórias póstumas de Brás Cubas e $O$ testamento do senhor Napumoceno.
\end{abstract}

ABSTRACT: Machado de Assis and Germano Almeida are representative writers in the literary scene in their countries, which besides having significant literary works, engaged in reflection of the construction of the literary system of their countries and participated in discussions about the training process. Thus, this paper aims to investigate the characteristics of these processes in both countries based on the reflection of the works The posthumous memoirs of Brás Cubas and The last will and testament of Senhor da Silva Araújo.

PALAVRAS-CHAVE: Literatura Comparada; Literatura Cabo-verdiana; Literatura Brasileira; Estudos culturais.

KEYWORDS: Comparative Literature, Literature Cape Verdean, Brazilian literature, cultural studies.

"...fui criado em um ambiente
onde não se falar francês era ser praticamente analfabeto.
Depois veio o inglês, passamos do francês para o inglês
e do inglês para a ignorância..."

Jorge Luis Borges

Os processos culturais, políticos e econômicos refletem diretamente na formação e consciência do sujeito como tal, que acompanha, se transforma e modifica esta movimentação. Desta forma, o sujeito atua diretamente nos processos, ao mesmo tempo em que é modificado por eles.

A literatura reflete acerca deste sujeito tanto na condição de ser social ou considerado como indivíduo, mediando a realidade e resultando num esquema de composição estético-ideológico. Manuel Veiga (apud. GOMES, 2008, p.52) ao apontar que "a carta de identidade de uma nação é, antes de mais, a sua cultura" conduz a reflexão de que, a literatura, arte da palavra, ao representar a subjetividade humana passada pelo filtro de percepção do autor, e caracterizada conforme o olhar deste

\footnotetext{
${ }^{1}$ Mestranda na Universidade Estadual Paulista "Júlio de Mesquita Filho"- UNESP, campus de Assis, com a pesquisa Processos culturais e literários na configuração das personagens Brás Cubas e Napumoceno, bolsista Fapesp. e-mail: guria_lange@ hotmail.com
} 
escritor perante a interpretação da realidade contribui no reconhecimento de um grupo social/cultural. Neste sentido:

[...] a obra de arte literária é um dado da cultura. A cultura é entendida como o conjunto de conhecimentos, atitudes, atividades, hábitos, recursos, técnicas, sentimentos, pensamentos e sensações de um grupo humano dentro de seu ambiente físico, social e psíquico. (ATAÍDE, 1972, p. 5).

Assim, investigar de que forma a literatura percebe o ser humano e o ficcionaliza é, antes de tudo, perceber os elementos composicionais da obra e como estes dialogam com os processos de sua época, visto que o fazer literário se insere dentre as produções culturais, além de refletir sobre a formação e consciência da identidade nacional.

Esta ideia de uma identidade nacional e de nacionalismo marcou a construção do sistema literário tanto no Brasil como em Cabo Verde. Para romper com a antiga metrópole lusitana, principalmente após a independência, esses países buscaram a sua identidade a partir de uma afirmação do nacional, de uma construção de sentido de 'nação', narrada, sobretudo pela cultura:

[...] as culturas nacionais, ao produzir sentidos sobre a 'nação', sentidos com os quais podemos nos identificar, constroem identidades. Esses sentidos estão contidos nas estórias que são contadas sobre a nação, memórias que conectam seu presente com seu passado e imagens que dela são construídas. (HALL, 2001, p.51.)

Nesta perspectiva, a literatura teve um papel fundamental na construção e solidificação do processo de ruptura. Segundo Eric Hobsbawm (2008), o termo nacionalismo é fundamental para o sustento da unidade política e nacional, pois é ele que gera a ideia do que se caracteriza por nação. Para que então se pudesse construir uma ideia de nação, em que o povo se reconhecesse parte de uma 'comunidade imaginada', era necessária a busca pelos elementos nacionais. Esta postura combativa em definir uma identidade coletiva era necessária para estimular o sentimento nacional e com isso desvincular-se por definitivo do colonizador. Para Stuart Hall, "[a] reafirmação de 'raízes' culturais e o retorno à ortodoxia tem sido, desde há muito, uma das poderosas fontes de contra-identificação em muitas sociedades e regiões póscoloniais e do Terceiro Mundo" (2001, p. 5).

Machado de Assis dizia que "não há dúvida que uma literatura, sobretudo uma literatura nascente, deve principalmente alimentar-se de assuntos que lhe oferece a sua região" (1955, p.135). No caso cabo-verdiano, por exemplo, "Manuel Ferreira associa a noção de consolidação da literatura com a de contestação à colonização portuguesa" (ANJOS, 2006, p.135). 
Tanto Brasil como Cabo Verde tiveram em comum a busca por uma nacionalidade que os desvinculasse da configuração colonial. Este sentimento de pertencimento a uma nação dava-se principalmente por meio da mediação da literatura, e da resistência necessária aos antigos modelos para a obtenção de uma literatura nacional. No entanto, Cabo Verde e Brasil diferenciam-se neste processo por mais de um século. Neste sentido, faz-se importante pensar na evolução da noção de identidade, afinal, "A identidade torna-se uma 'celebração móvel' forma e transforma continuamente em relação às formas pelas quais somos representados ou interpelados nos sistemas culturais que nos rodeiam" (HALL, 2001, p.13).

No século XVIII o Iluminismo modificou muito dos pensamentos vigentes da época, trazendo uma mudança de perspectiva e alterando a concepção de sujeito até então conhecida, bem como da própria literatura:

Essa mudança de perspectiva se dá a partir de uma série de circunstâncias que cercam o final do século XVIII e praticamente todo o século XIX [...] É também neste momento que o romance se desenvolve e se modifica, coincidindo com a afirmação de um novo público - o público burguês - caracterizado, entre outras coisas, por um gosto artístico particular. (BRAIT, 2006, p.37).

$\mathrm{O}$ nascimento do 'indivíduo soberano', entre o Humanismo renascentista do século XVI e o Iluminismo do século XVIII, representou uma ruptura importante com o passado. Alguns argumentam que ele foi o motor que colocou todo o sistema social da 'modernidade' em movimento. (HALL, 2001, p.25).

Desta forma, a França, que já servia de ponte entre as artes mundiais e os jovens intelectuais brasileiros, conquistava adeptos na ex-colônia lusa, sendo pelos intelectuais da época vista como o grande modelo e como sinônimo de erudição.

Com isso, ao distanciar-se da metrópole, e na expectativa da definição de uma arte nacional, as ex-colônias precisaram buscar outros referenciais que já haviam se consolidado no âmbito cultural para assim nortear a construção do sentimento de nação e de sua cultura:

O colonialismo, assim, é aquele momento em que uma metrópole assume o controle político econômico da colônia; quando ocorre a ruptura dessa relação, as práticas sociais antes exercidas continuam a assombrar e moldar a esfera cultural, como ideologia fantasmagórica, garantindo um "neocolonialismo" na nova ordem política e econômica. O neocolonialismo implantado surge como resposta a um vazio cultural sustentado pela presença autoritária da antiga metrópole, que como parte da empreitada colonialista, visava desprover a população nativa da possibilidade de auto-suficiência. Os colonizadores, após sua retirada política desses países, continuaram a governá-los intelectualmente. Em outras palavras, como aponta Shaobo Xie (1997), os antigos países colonizados enfrentam o 
neocolonialismo que se instala por meio da hegemonização da economia, tecnologia e ideologia ocidentais.

(SAMPAIO, 2008, p. 80-81).

Assim sendo, a presença francesa no Brasil colaborou com a tentativa de construção da literatura nacional brasileira servindo de referência, modelo e, como disse Machado de Assis (1879), como principal “influxo externo” para a produção literária e intelectual do país. No ensaio A nova geração o próprio Machado comenta sobre a utilização das novas tendências européias pelos escritores: "A nova geração frequenta os escritores da ciência; não há poeta digno desse nome que não converse um pouco, ao menos, com os naturalistas e filósofos modernos.”. (ASSIS, 1879).

Portanto, inserida neste panorama, a obra de Machado de Assis, Memórias póstumas de Brás Cubas (1881), dialoga com estas ideias circulantes, discutindo-as, acima de qualquer outro recurso, pela ironia:

[...] o melhor ponto de partida são as Memórias póstumas de Brás Cubas, não só pela posição central - em todos os sentidos - que este romance ocupa na produção do autor, como porque nele, mais do que em qualquer outra obra, os mecanismos da visão irônica se fazem presentes. (ALMEIDA, 1994, p.82)

A personagem Brás Cubas apresenta ao longo de todo romance, teorias francesas (a presença francesa em Memórias póstumas de Brás Cubas foi motivo de estudos) que eram reproduzidas no território brasileiro, além de suas próprias teorias filosóficas que, em grande parte, parodiavam as anteriores.

Considerada pelos críticos um romance moderno por seu conteúdo e inovação de escrita, Memórias póstumas de Brás Cubas representa um marco tanto na fortuna crítica do escritor quanto para a própria literatura brasileira. Além disso, a obra ainda aborda características multiculturais presentes na formação do sujeito e em seu reconhecimento de identidade nacional brasileira. Era difícil se pensar em nacionalidade sem levar em conta os fatores e culturas exógenas que invadiam o país e caracterizavam, sobretudo, a sociedade burguesa da época.

Também na construção da nacionalidade cabo-verdiana teve-se a presença de elementos externos, ocasionada, sobretudo, pela migração constante aos Estados Unidos e do panorama mundial da globalização. Com a ampliação do comércio internacional, do acúmulo de capital e ascensão da burguesia, o capitalismo se consolidou e os Estados Unidos solidificaram-se como um dos novos e maiores impérios mundiais:

Ninguém negou que o detentor do maior poder dentro dessa configuração são os Estados Unidos, seja porque um pequeno número 
de multinacionais americanas controla a produção, a distribuição e, sobretudo, a seleção de notícias em que a maior parte do mundo acredita, seja porque a expansão desenfreada de várias formas de controle cultural originadas dos Estados Unidos criou um mecanismo de incorporação e dependência cujo objetivo é subordinar e se impor não só a um público americano interno, mas também a culturas menores e mais fracas." (SAID, 1993, p.36)

Neste cenário, e conquistada a independência em 1974, Cabo Verde e os caboverdianos viam-se sem muitas alternativas para o sustento diante de terras improdutivas e da prejudicada condição geográfica insular. A solução acabou sendo a migração para os Estados Unidos a fim de, além das possibilidades de estudo e de formação, obter renda e sustento para os que ficavam nas ilhas. Diante deste quadro, entender a caboverdianidade como algo unificado era praticamente impossível, apesar da cultura ser o principal fator de união e diálogo entre os cabo-verdianos. As identidades híbridas, portanto, faziam-se cada vez mais representativas neste fluxo migratório e neste panorama de transformações sociais-culturais-políticas, além é claro, da própria questão racial da mestiçagem marcadamente constituidora do cabo-verdiano:

Essas transformações estão também mudando nossas identidades pessoais, abalando a ideia que temos de nós próprios como sujeitos integrados. Esta perda de um 'sentido de si' estável é chamada, algumas vezes, de deslocamento-descentração do sujeito. Esse duplo deslocamento-descentração dos indivíduos tanto de seu lugar no mundo social e cultural quanto de si mesmos constitui uma 'crise de identidade' para o indivíduo. (HALL, 2001, p. 9)

Desta forma, a noção de identidade individual e de identidade nacional sofria com as mudanças que colocavam os indivíduos numa configuração multicultural e fragmentada, pois como observa Stuart Hall “"a]s identidades nacionais estão se desintegrando, como resultado do crescimento da homogeneização cultural e do 'pósmoderno' global" (HALL, 2001, p.69).

Inserida neste panorama, a obra de Germano Almeida $O$ testamento do senhor Napumoceno (1989) traz como personagem central um homem que enriqueceu pelo acaso e que, a partir de sua ida aos Estados Unidos, comentava sua percepção do estrangeiro e de como se deslumbrara por certas coisas deste país. Descrita por Manuel Veiga (1998, p. 5) como sendo "uma das mais representativas obras da moderna literatura cabo-verdiana", o romance, entre ironias e história, apresenta questões referentes aos aspectos sociais, políticos, econômicos e culturais de Cabo-Verde.

Assim sendo, ao comporem personagens individuais, Machado de Assis e Germano Almeida, alcançaram transcendência para discussão do ser social, refletindo, 
num projeto estético original, as transformações sociais, culturais, políticas e econômicas de uma nação. Essas figuras ficcionais colaboram para a reflexão de todo um período de transformações em âmbito global, concentrados na representação de um anti-herói desmontado pela ausência de atitudes gloriosas e marcadas pelo tom irônico da narrativa.

Desta forma, as obras aqui expostas para discussões, mesmo separadas por demarcações geográficas e temporais, demonstram um entrecruzar entre Brasil e Caboverde no que concernem os processos culturais e a formação de seu sistema literário, tendo em vista a formação colonialista de ambos os países e a atuação crítica dos escritores na reflexão de uma identidade nacional e dos processos literários.

\section{REFERÊNCIAS BIBLIOGRÁFICAS}

ALMEIDA, Germano. O Testamento do Senhor Napumoceno. São Paulo: Companhia das Letras, 1996.

ALMEIDA, José Maurício Gomes de. "A visão irônica nas Memórias póstumas de Brás Cubas." In: VÁRIOS AUTORES. Machado de Assis - Estudos de Literatura Brasileira. Especial número 4. Rio de Janeiro: Faculdade de Letras/UFRJ, 1994.

ANJOS,J.C.G dos. Intelectuais, literatura e poder em Cabo Verde: lutas de definição da identidade nacional. Porto Alegre: Ed. UFRGS, 2006.

ASSIS, Machado de. Memórias póstumas de Brás Cubas. São Paulo: Ática, 2001.

ATAÍDE, Vicente. A narrativa de ficção. Curitiba: Ed. Dos professores, 1972.

BRAIT, Beth. A personagem. São Paulo: Ática, 2006.

GOMES, Simone Caputo. Cabo Verde: literatura em chão de cultura. Cotia: Ateliê, 2008 .

HALL, Stuart. A identidade cultural na pós-modernidade. Rio de Janeiro: DP\&A, 2001.

HOBSBAWM, Eric. Nações e nacionalismos: desde 1780. São Paulo: Paz e Terra, 2008.

SAID, Edward. Cultura e imperialismo. São Paulo: Companhia das Letras, 1995.

SAMPAIO, Alexandre. O olhar pós-colonial na construção de uma identidade irlandesa: um estudo da peça Translations, de Brian Friel. 2008. 248 f. Dissertação (Mestrado) - Instituto de Biociências, Letras e Ciências Exatas: Universidade Estadual Paulista, 2008.

SCHWARZ, Roberto. Um mestre na periferia do capitalismo. São Paulo: Duas Cidades, 1990. 